\title{
Percepção dos produtores rurais quanto práticas agroecológicas utilizadas na criação animal no município de Queimadas-Paraíba
}

\author{
Amadeu Pimentel Travassos ${ }^{1}$, Jean Flaviel de Sousa Macêdo', Ivo Marcelino Passos Netol, Luana de Fátima \\ Damasceno dos Santos $*^{2}$
}

${ }^{1}$ Universidade Estadual da Paraíba; amadeutravassos@gmail.com; jeanfsm@gmail.com; ivo_cg@hotmail.com; *2 Universidade Federal de Paraíba, luana_jppb@yahoo.com.br.

\begin{abstract}
RESUMO: Para que as práticas agroecológicas na criação animal, principalmente na região semiárida, sejam mais efetivas, torna-se necessário a diminuição da resistência dos produtores rurais quanto ao seu emprego, bem como a simplificação das informações e práticas agroecológicas aos produtores. Neste sentido, objetivou-se a partir desta pesquisa caracterizar a percepção dos produtores rurais do município de Queimadas/PB quanto as práticas agroecológicas empregadas na criação animal. A pesquisa foi desenvolvida e aplicada a produtores rurais do município de Queimadas/PB. A base de escolha do município de aplicação da pesquisa deteve-se em função da participação dos produtores na criação animal nessa região. Há produtores rurais de Queimadas-PB que utilizam manejo agroecologico mas possuem o conhecimento generalizado de que suas práticas são agroecológicas Dificuldades apresentadas pelo ambiente, como escassez de chuvas e pouca disponibilidade de forragens, levam os criadores procurarem métodos mais rápidos de enfrentarem esses problemas. Falta de assistência técnica com enfoque agroecológico e projetos rurais, que mostrem aos produtores que esse tipo de manejo funciona, devem possuir incentivos, afim de tornar as criações mais sustentáveis, gerando o mínimo de problemas ambientais e custos ao produtor.
\end{abstract}

PALAVRAS-CHAVE: Produção orgânica; Agroecologia; Caracterização de produtores.

\section{INTRODUÇÃO}

O constante aumento da população associada com a necessidade de produzir cada vez mais alimentos, promoveu uma expansão rápida da agricultura e pecuária moderna ou convencional. Consequentemente, o aumento do número de impactos ambientais está correlacionado a esses fatos, tendo-se em vista, que os produtores desconsideram o meioambiente em prol dos lucros (ALTIERI, 2002).

$\mathrm{Na}$ perspectiva abordada, medidas paliativas começaram a ser analisadas e desenvolvidas com o intuito de se criar uma forma de agropecuária que fosse sustentável, com preocupação no sentido produtivo, associado ainda a preocupação ambiental. Os princípios dessa nova forma de agropecuária iriam mais além do que mera prática conservacionista, através do desenvolvimento de uma agropecuária sobre preceitos sociológicos, filosóficos e igualitários, conhecida como agroecologia.

A criação animal é expressiva no semiárido nordestino, principalmente ao se tratar de caprinos e ovinos, por deter um dos maiores rebanhos nacionais (PPM, IBGE, 2016). Na visão agroecológica, essa produção animal, como a caprinovino cultura orgânica, é um sistema saudável de produção de alimentos, que tem a preocupação de preservar o meio ambiente, e integrado à produção vegetal, visa à reciclagem de nutrientes e uma maior independência de insumos vindos de fora da propriedade.

Porém, em função da falha de informações e até mesmo desinformação dos produtores rurais quanto aos aspectos conceituais de base agroecológica na criação animal e suas aplicações, estas possibilitam uma diminuição efetiva das práticas agroecológicas aplicadas por estes, embora saibam a importância de sua implantação, seja no aspecto de preservação dos recursos naturais, bem como diminuição dos custos de produção.

Para que as práticas agroecológicas na criação animal, principalmente na região semiárida, sejam mais efetivas, torna-se necessário a diminuição da resistência dos produtores rurais quanto ao seu emprego, bem como a simplificação das informações e práticas agroecológicas aos produtores.

Neste sentido, objetivou-se a partir desta pesquisa caracterizar a percepção dos produtores rurais do município de Queimadas/PB quanto as práticas agroecológicas empregadas na criação animal.

\section{MATERIAL E MÉTODOS}

Foi realizada uma pesquisa do tipo 'Survey' (Francisco et al., 2007), na qual é utilizada para obtenção de informações por intermédio de entrevista individual com os produtores rurais, com elaboração e aplicação de perguntas acerca da temática quanto a percepção destes no uso de práticas agroecológicas na criação animal, por meio de aplicação de questionário estruturado para obter uma padronização do processo de coleta de dados.

A pesquisa foi desenvolvida e aplicada a produtores rurais do município de Queimadas/PB, cuja coordenadas geográficas são latitude $07^{\circ} 21^{\prime} 30^{\prime}$ 'S e longitude $35^{\circ} 53^{\prime} 54^{\prime}$ 'W , localizado na região metropolitana de Campina Grande. 
TRAVASSOS, A. P. et al. Percepção dos produtores rurais quanto práticas agroecológicas utilizadas na criação animal no município de Queimadas-Paraíba. In: II Congresso Paraibano de Agroecologia \& IV Exposição Tecnológica, 2019. Anais... Caderno Verde de Agroecologia e Desenvolvimento Sustentável, Pombal, v. 9, n.7, e-7053, 2019.

A base de escolha do município de aplicação da pesquisa deteve-se em função da participação dos produtores na criação animal nessa região, como abordado por dados referentes a pesquisa pecuária municipal (PPM, IBGE, 2017) (tabela 1).

Tabela 1. Efetivo do rebanho a nível nacional, estadual e municipal (Queimadas/PB).

\begin{tabular}{lrlrrrr}
\hline \multirow{2}{*}{$\begin{array}{c}\text { Brasil, Unidade } \\
\text { da Federação e } \\
\text { Município }\end{array}$} & \multicolumn{1}{c}{ Bovino } & \multicolumn{1}{c}{ Equino } & \multicolumn{1}{c}{ Suíno } & \multicolumn{1}{c}{ Caprino } & \multicolumn{1}{c}{ Ovino } & Galináceos \\
\cline { 2 - 7 } & 214.899 .796 & 5.501 .872 & 41.099 .460 & 9.592 .079 & 17.976 .367 & 1.425 .699 .944 \\
\hline $\begin{array}{l}\text { Brasil } \\
\text { Paraíba }\end{array}$ & 1.202 .781 & 55.965 & 199.884 & 613.919 & 572.688 & 10.783 .725 \\
Queimadas (PB) & 14.957 & 650 & 5.500 & 2.700 & 6.200 & 110.241 \\
\hline
\end{tabular}

O questionário foi aplicado por meio de entrevista direta a 69 famílias de produtores da zona rural, junto a Prefeitura Municipal de Queimadas, que auxiliou na distribuição e direcionamento das propriedades, durante todo o mês de outubro/2018.

O questionário apresentou 42 questões, sendo elas abertas e de múltipla escolha, divididas em 4 segmentos. O primeiro segmento objetivou-se a realização de dados quanto ao levantamento socioeconômico das famílias e sua caracterização; seguida da identificação das propriedades quanto a atividade realizada, criação de animais, área para criação/cultivo, quantidade de animais e avaliação das dificuldades encontradas para prosseguir na criação. $\mathrm{O}$ terceiro segmento constituiu de questões relacionadas aos tratos culturais e práticas agropecuárias. O quarto, por fim, objetivouse caracterizar a percepção e o conhecimento dos produtores rurais quanto as práticas agroecológicas na criação animal.

Nesse sentido, os questionamentos permitiram verificar aspectos inerentes ao perfil dos produtores rurais, bem como caracterização de sua atividade pecuária e os conhecimentos tomados quanto as práticas agroecológicas aplicadas ou não.

Após a realização das entrevistas, e levantamentos dos dados, estes foram tabulados, com uso de uma planilha do aplicativo Excel (2010), sendo os dados expressos em valores percentuais na base de tabelas e gráficos. Os dados foram submetidos a uma análise estatística descritiva, dando ênfase na distribuição das frequências relativas às respostas obtidas nas entrevistas.

\section{RESULTADOS E DISCUSSÃO}

Pessoa et al. (2018) apontam que a aplicação de questionários em pesquisas de investigação sistemática é utilizada para caracterizar a opinião direta de uma população sobre um assunto. Porém, a pesquisa por meio da aplicação de questionários está sujeita as limitações, quanto ao tamanho da amostra utilizada, falta do método estatístico de amostragem mais adequada para aplicação e variabilidade das interpretações na realização da pesquisa. Kirinus et al. (2013) correlata ainda que esta pesquisa limita as generalizações, porém, não invalida a pesquisa como sinalizadora de tendências, e deficiências observadas.

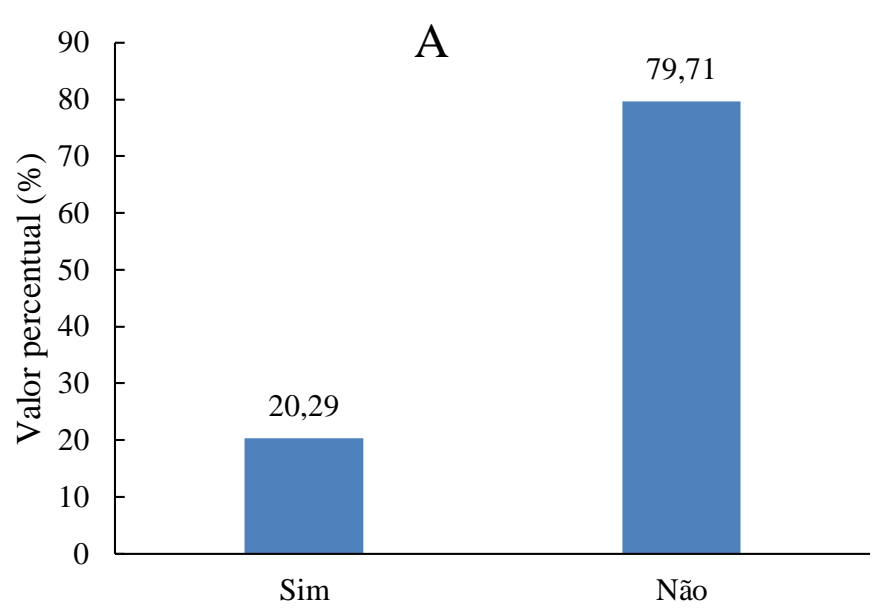

Conhecimento quanto ao significado das práticas agroecológicas
B

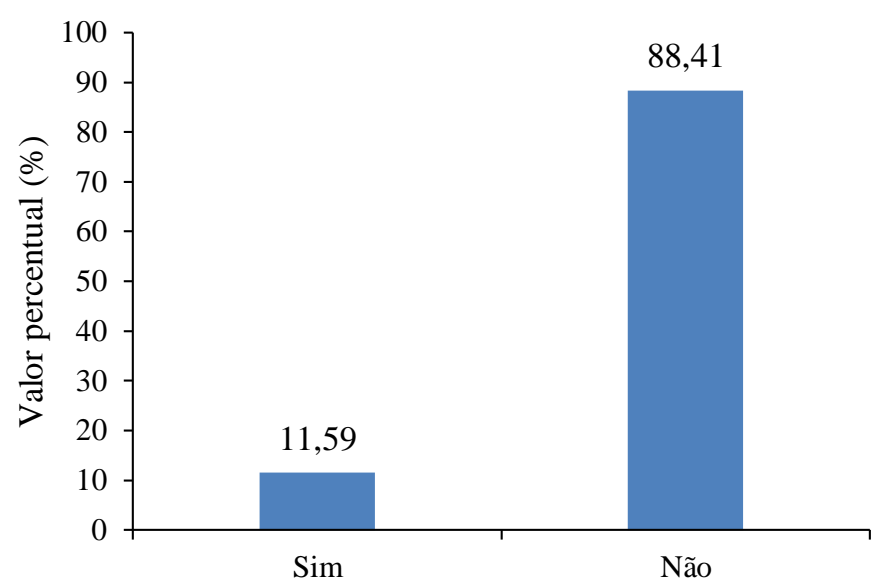

Existência das práticas agroecológicas na criação animal 
TRAVASSOS, A. P. et al. Percepção dos produtores rurais quanto práticas agroecológicas utilizadas na criação animal no município de Queimadas-Paraíba. In: II Congresso Paraibano de Agroecologia \& IV Exposição Tecnológica, 2019. Anais... Caderno Verde de Agroecologia e Desenvolvimento Sustentável, Pombal, v. 9, n.7, e-7053, 2019.

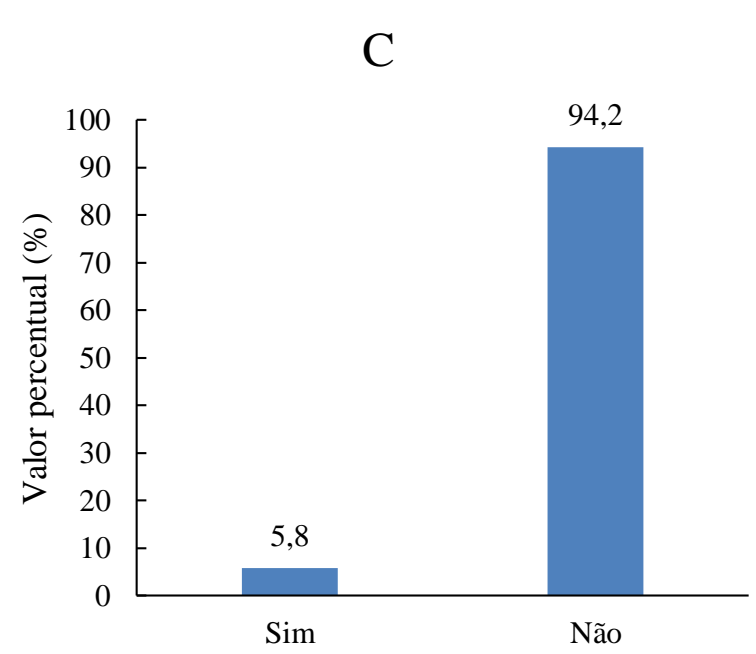

Faz uso de práticas agroecológicas

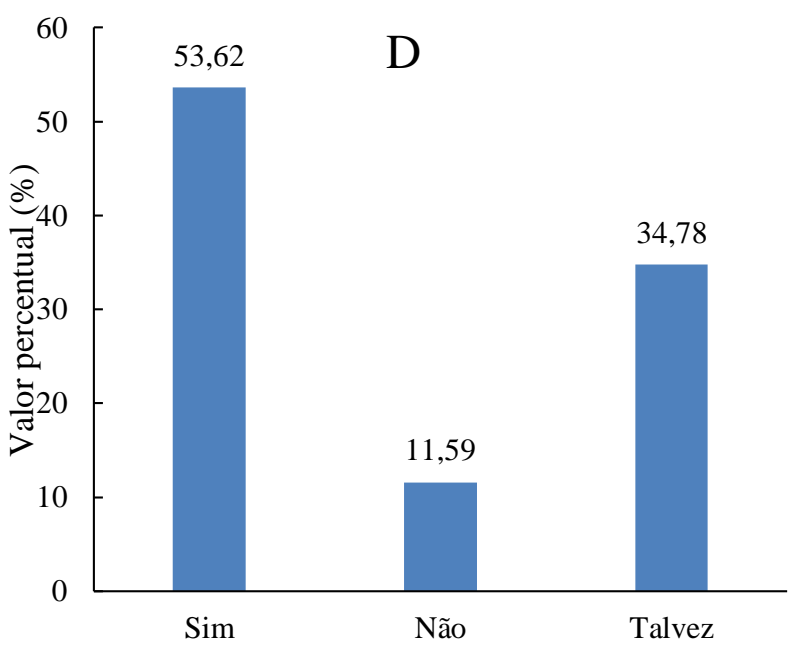

Adequação do manejo animal agroecologico

Questionados quanto ao conhecimento do significado de práticas agroecológicas (Gráfico 1A), aproximadamente $80 \%$ desconhecem o termo. Outros, cerca de $21 \%$, já ouviram ou presenciaram tais práticas, seja em outras propriedades, seja no meio acadêmico. Relacionando com a criação animal, esse índice é crescente, chegando a quase $89 \%$ de desconhecimento sobre as práticas agroecológicas na criação animal (gráfico 2B). 11,59\% dizem conhecer a existências delas na criação animal. Pode-se relacionar esses resultados com o do gráfico B, como a não utilização de insumos químicos nas forragens.

$\mathrm{Na}$ criação animal, é recomendado que os sistemas de produção adotem práticas de manejo orgânico, menos agressivos e que tem por objetivo a auto sustentação do produtor. O manejo animal nesse sistema tem como princípios, a atenção à qualidade de vida e o bem-estar do animal, contrariando más instalações e baixa higiene em todo o processo criatório. Quanto ao uso de práticas agroecológicas (gráfico 2C), o resultado não diferiu dos demais. Aproximadamente 95\% dos produtores desconhecem o termo. Este resultado condiz com boa parte das propriedades do estado da Paraíba por ser um termo novo no ambiente rural. Altieri (2004) afirma que a agroecologia supri estruturas de trabalho para uma compreensão profunda da natureza e seus agroecossistemas, agregando princípios agronômicos, ecológicos, zootécnicos e socioeconômicos.

Por último, indagou-se aos proprietários a possibilidade de adequação ao manejo animal agroecológico (gráfico 2D). 53,62\% informaram que, futuramente, poderiam aderir a prática agroecológica e apenas 11,59\% não se adequariam ao novo tipo de manejo animal.

Por serem propriedades com baixa disponibilidade de terras e terem a maior parte do conhecimento passado pelos pais, avós, etc, os produtores apresentam algumas limitações e resistência à este tipo de prática. Os produtores possuem necessidades quanto ao conhecimento das práticas, diante da vasta dificuldade em manejá-los em bases agroecológicas. Medicamentos, insumos e alimentações convencionais possuem um fácil acesso quando comparados a métodos alternativos, adicionando também o custo de compra desses produtos. Preservação do meio ambiente quando relacionado ao pastejo e métodos de conservação do solo, disponibilidade de uma flora rica em plantas com alegações medicinais, métodos de captação de água para uso animal e humano, são alguns benefícios que a produção animal agroecológica tras consigo. Porém, devido à falta de conhecimento por parte de alguns produtores e de assistência técnica, a criação animal com bases agroecológicas ainda engatinha na cidade pesquisada.

\section{CONCLUSÕES}

A falta de conhecimentos agroecológicos nas propriedades entrevistas gera problemáticas envolvendo a saúde dos animais, do solo e aos ecossistemas integrantes dos locais de produção.

A produtores rurais de Queimadas desenvolvem alguns processos agroecológicos, mas possuem o conhecimento generalizado de que suas práticas são agroecológicas. Dificuldades apresentadas pelo ambiente, como escassez de chuvas e pouca disponibilidade de forragens, levam os criados a procurarem métodos mais rápidos de enfrentarem esses problemas. Falta de assistência técnica, com enfoque em agroecologia e projetos rurais que mostrem aos produtores que esse tipo de manejo funciona, devem possuir incentivos, afim de tornar as criações mais sustentáveis, gerando o mínimo de problemas ambientais e custos ao produtor. 
TRAVASSOS, A. P. et al. Percepção dos produtores rurais quanto práticas agroecológicas utilizadas na criação animal no município de Queimadas-Paraíba. In: II Congresso Paraibano de Agroecologia \& IV Exposição Tecnológica, 2019. Anais... Caderno Verde de Agroecologia e Desenvolvimento Sustentável, Pombal, v. 9, n.7, e-7053, 2019.

\section{REFERÊNCIAS}

ALTIERI, M. Agroecologia: bases científicas para uma agricultura sustentável. Guaíba/RS, Rio Grande do Sul: Ed. Agropecuária, 2002.

ALTIERI, M. A., NICHOLLS, C. I., HENAO, A. \& LANA, M. A. Agroecology and the design of climate changeresilient farming systems. Agronomy for SustainableDevelopment, n. 1, v.35, p. 869-890, 2015.

FRANCISCO, M. F. A. C. Agricultura Orgânica: regulamentos técnicos e acesso aos mercados dos produtos orgânicos no Brasil. Niterói (RJ): PESAGRO RIO, 2009. 119p.

KIRINUS, J.B. Web Semântica. Encontros Bibli: Revista Eletrônica de Biblioteconomia e Ciência da Informação, Florianópolis, n.18, p.20-39, 2013.

PESSOA, Louis; MANION, Lawrence; MORRISON, Keith. Research methods in education. 7th ed. Routledge, 2018.

\section{AGRADECIMENTOS}

Apoio financeiro: Fundação de Apoio à Pesquisa do Estado da Paraíba - FAPESQ. 